\title{
Lotus japonicus flowers are defended by a cyanogenic -glucosidase with highly restricted expression to essential reproductive organs
}

Lai, Daniela; Pimanová, Martina; Abou Hachem, Maher ; Motawia, Mohammed Saddik; Olsen, Carl Erik; Møller, Birger Lindberg; Rook, Fred; Takos, Adam M.

Published in:

Plant Molecular Biology

Link to article, DOI:

$10.1007 / \mathrm{s} 11103-015-0348-4$

Publication date:

2015

Document Version

Peer reviewed version

Link back to DTU Orbit

Citation (APA):

Lai, D., Pimanová, M., Abou Hachem, M., Motawia, M. S., Olsen, C. E., Møller, B. L., Rook, F., \& Takos, A. M. (2015). Lotus japonicus flowers are defended by a cyanogenic -glucosidase with highly restricted expression to essential reproductive organs. Plant Molecular Biology, 89(1-2), 21-34. https://doi.org/10.1007/s11103-015$0348-4$

\section{General rights}

Copyright and moral rights for the publications made accessible in the public portal are retained by the authors and/or other copyright owners and it is a condition of accessing publications that users recognise and abide by the legal requirements associated with these rights.

- Users may download and print one copy of any publication from the public portal for the purpose of private study or research.

- You may not further distribute the material or use it for any profit-making activity or commercial gain

- You may freely distribute the URL identifying the publication in the public portal 


\section{Lotus japonicus flowers are defended by a cyanogenic $\beta$-glucosidase with highly restricted expression to essential reproductive organs}

Daniela Lai ${ }^{1}$, Martina Pičmanová ${ }^{1}$, Maher Abou Hachem², Mohammed Saddik Motawia ${ }^{1}$, Carl Erik Olsen ${ }^{1}$, Birger Lindberg Møller ${ }^{1,3}$, Fred Rook $^{1}$ and Adam M. Takos ${ }^{1,4^{*}}$

${ }^{1}$ Plant Biochemistry Laboratory, Department of Plant and Environmental Sciences, University of Copenhagen, 1871

Frederiksberg C, Denmark

${ }^{2}$ Department of Systems Biology, Technical University of Denmark, 2800 Kongens Lyngby, Denmark

${ }^{3}$ Carlsberg Laboratory, Gamle Carlsberg Vej 10, 1799 Copenhagen V, Denmark

${ }^{4}$ Evolva Copenhagen, Lersø Parkallé 42-44, 2100 Copenhagen Ø, Denmark

* Corresponding author

Email addresses:

Daniela Lai

dal@plen.ku.dk

Martina Pičmanová

marpi@plen.ku.dk

Maher Abou Hachem

maha@bio.dtu.dk

Mohammed Saddik Motawia

mosm@plen.ku.dk

Carl Erik Olsen

ceo@plen.ku.dk

Birger Lindberg Møller

blm@plen.ku.dk

Fred Rook

frro@plen.ku.dk

*Adam M. Takos

adamt@evolva.com

Telephone: +4535331134

Fax: +4535333300 


\begin{abstract}
Flowers and leaves of Lotus japonicus contain $\alpha-, \beta$-, and $\gamma$-hydroxynitrile glucoside (HNG) defense compounds, which are bioactivated by $\beta$-glucosidase enzymes (BGDs). The $\alpha$-HNGs are referred to as cyanogenic glucosides because their hydrolysis upon tissue disruption leads to release of toxic hydrogen cyanide gas, which can deter herbivore feeding. BGD2 and BGD4 are HNG metabolizing BGD enzymes expressed in leaves. Only BGD2 is able to hydrolyse the $\alpha$-HNGs. Loss of function mutants of $B G D 2$ are acyanogenic in leaves but fully retain cyanogensis in flowers pointing to the existence of an alternative cyanogenic BGD in flowers. This enzyme, named BGD3, is identified and characterized in this study. Whereas all floral tissues contain $\alpha$-HNGs, only those tissues in which $B G D 3$ is expressed, the keel and the enclosed reproductive organs, are cyanogenic. Biochemical analysis, active site architecture molecular modelling, and the observation that L. japonicus accessions lacking cyanogenic flowers contain a non-functional BGD3 gene, all support the key role of BGD3 in floral cyanogenesis. The nectar of $L$. japonicus flowers was also found to contain HNGs and additionally their diglycosides. The observed specialisation in HNG based defence in L. japonicus flowers is discussed in the context of balancing the attraction of pollinators with the protection of reproductive structures against herbivores.
\end{abstract}

Key words: cyanogenesis defense, $\beta$-glucosidase, hydroxynitrile glucosides, florivory, Lotus japonicus, toxic nectar

\author{
Abbreviations: \\ BGD: $\beta$-glucosidase \\ Cyd: cyanogenesis deficient \\ CYP: cytochrome P450 \\ HNG: hydroxynitrile glucoside \\ HNdG: hydroxynitrile diglycoside \\ $\mathrm{m} / \mathrm{z}$ : mass to charge ratio \\ RT-qPCR: quantitative real-time PCR
}




\section{INTRODUCTION}

Plants use a range of different flower colours, shapes and odors to attract pollinators, which are rewarded with nectar as a primary source of nutrition (Heil, 2011). Some undesirable floral visitors feed on flower tissues or damage these tissues as they seek nectar or pollen without contributing to pollination (McCall and Irwin, 2006; Irwin et al., 2010). As with other plant tissues, flowers may also be eaten by generalist herbivores (McCall and Karban, 2006). Damaged flowers are less appealing to pollinators and they are visited less often, leading to lower reproductive success (Krupnick et al., 1999).

Considering the essential role of flowers in reproduction and based on assumptions from 'optimal defense theory', significant resources would be expected to be allocated for their protection by defensive metabolites (Ohnmeiss and Baldwin, 2000). For example, the total concentration of glucosinolates are higher in petals than leaves of Raphanus sativas (Straus et al., 2004); cyclic hydroxamic acids are found in high amounts in the stamen compared to leaves of Acanthus mollis (Bravo and Copaja, 2002); monoterpenoids are found in high levels in flowers of Thymus capitatus (Tawaha and Hudaib, 2012); proanthocyanidins accumulate in flowers but not leaves of the model legume Lotus japonicus (Gruber et al., 2008) and in flowers of white clover (Foo et al., 2000); and the alkaloid galanthamine is highly biosynthesized by tissues from ovary walls and flower stalks of Leucojum aestivum (Eichhorn et al., 1998).

Cyanogenic glucosides are $\alpha$-hydroxynitrile glucoside (HNG) defense compounds derived from amino acids and are widely distributed in the plant kingdom from ferns to gymnosperms and angiosperms (Bak et al., 2006; Gleadow and Møller, 2014). The $\alpha$-HNGs are converted to active defense compounds by the action of $\beta$-glucosidases (BGDs), which hydrolyze the $O$-linked glycosidic bond to release glucose and $\alpha$-hydroxynitrile aglycone. The $\alpha$ hydroxynitrile subsequently dissociates, either by the action of hydroxynitrile lyase enzymes, or spontaneously due to its inherent chemical instability, to release hydrogen cyanide and a ketone compound (Zagrobelny et al., 2004; Morant et al., 2008). The $\alpha$-HNGs and their activating BGDs form a spatially separated two-component defense system that is activated upon tissue disruption and mixing of the components, for example by herbivore feeding (Hughes et al., 1992; Gruhnert et al., 1994; Morant et al., 2008; Møller, 2010).

Over 3000 different plant species have been reported to contain $\alpha$-HNGs, with most studies and surveys concentrating on foliar tissues (Harper et al., 1976; Conn, 1981; Lewis and Zona, 2000; Forslund et al., 2004; Miller et al., 2006; Blomstedt et al., 2012; Miller and Tuck, 2013; Neilson et al., 2015) or the edible parts of food crops (Jones, 1998; Nielsen et al., 2002; Jørgensen et al., 2005). There are relatively few reports of the occurrence of $\alpha$ HNGs in flower tissues but in Grevillea species, Linum usitatissimum (flax), L. japonicus, Ryparosa kurrangii (rainforest tree) and Eucalyptus camphora they accumulate in equivalent or higher levels than foliar tissues (Lamont, 1994; Niedźwiedź-Siegień, 1998; Forslund et al., 2004; Webber and Woodrow, 2008; Neilson et al., 2011). The investment of resources to biosynthesize $\alpha-H N G$ in these cases suggests they can be added to the various classes of secondary metabolites that have an important role in the defense of flowers (Neilson et al., 2013).

L. japonicus biosynthesizes the $\alpha$-HNGs lotaustralin and linamarin, as well as non-cyanogenic $\gamma$ - and $\beta$-HNGs branching from the same pathway, named rhodiocyanoside A and rhodiocyanoside D, respectively (Forslund et al., 2004; Takos et al., 2011). Two paralogous HNGs metabolising BGDs, BGD2 and BGD4, are expressed in the leaves of L. japonicus, but differ in their ability to hydrolyse $\alpha$-HNGs (Takos et al., 2010; Lai et al., 2014). A leaf-based 
genetic screen for cyanogenesis deficient (cyd) mutants identified several alleles of the cyd2 mutant, defective in the $B G D 2$ gene, demonstrating its exclusive role in cyanogenesis in vegetative tissues (Takos et al., 2010). Biochemical assays of recombinant expressed proteins confirmed that only BGD2 could hydrolyse the cyanogenic $\alpha$-HNG lotaustralin, whereas both BGD2 and BGD4 could hydrolyse the non-cyanogenic $\gamma$-HNG rhodiocyanoside A. Sitedirected mutagenesis studies demonstrated that a single amino acid polymorphism in the aglycone binding region of the active site, specifically G211 in BGD2 and V211 in BGD4, was sufficient to explain the difference in substrate specificity between both enzymes for the $\alpha$-HNGs lotaustralin and linamarin (Lai et al., 2014).

In this study we have identified and characterized an additional cyanogenic BGD from L. japonicus, BGD3, which is tissue specifically expressed in flowers. The full-length sequence of the $B G D 3$ gene is not present in the current draft version of the L. japonicus genome sequence (Sato et al., 2008; http://www.kazusa.or.jp/lotus) but was cloned by RACE PCR from cDNA using partial sequence information. The specific expression of BGD3 in flower tissue suggests that it plays a pivotal role in defense of flower structures to ensure reproductive success.

\section{MATERIALS AND METHODS}

\section{Plant material}

L. japonicus seeds for wild type MG20 and natural accessions were obtained from Legume Base at Miyazaki University, Japan (http://www.legumebase.brc.miyazaki-u.ac.jp/). L. japonicus cyd mutants have previously been described (Takos et al., 2010). Seeds were germinated on wet filter paper, seedlings grown in the dark for 3-5 days, exposed to light for 1 day and then transferred to soil and grown in a glasshouse under a $16 \mathrm{~h}$ light cycle at $22^{\circ} \mathrm{C}$. Nicotiana benthamiana seed were directly sown on soil and plants grown in a glasshouse under conditions as above. Flax seeds (L. usitatissimum) were kindly provided by Steen Malmmose.

\section{Chemicals}

The substrates lotaustralin and rhodiocyanoside A were purified by preparative HPLC from L. japonicus MG20 leaf material (Bjarnholt et al., 2008). Linamarin and amygdalin were purchased from Sigma-Aldrich. Prunasin was chemically synthesized in our own laboratory by Dr M.S. Motawia.

\section{Detection of cyanogenesis with Feigl-Anger Paper}

Feigl-Anger paper (Feigl and Anger, 1966) was prepared as described in Takos et al., 2010. Plant tissue was ground in $300 \mu \mathrm{l}$ of $20 \mathrm{mM}$ MES buffer, $\mathrm{pH} 6.5$ in 96 well plates and exposed to Feigl-Anger paper. After incubation for 30 $\min$ to $2 \mathrm{~h}$ at $25^{\circ} \mathrm{C}$, the paper was removed and cyanogenesis scored by the development of blue colour. A permanent record was made by scanning the paper.

\section{LC-MS Analysis}


Plant tissues (individual whole flowers, flower structures and leaves) were boiled in $85 \%(\mathrm{v} / \mathrm{v}) \mathrm{MeOH}(300 \mu \mathrm{l})$ in a water bath for $5 \mathrm{~min}$ and cooled on ice. The extracts were centrifuged at 18,000 x $g$ for $1 \mathrm{~min}$, filtered through a 0.45 $\mu \mathrm{m}$ PVDF filter (Millipore) and diluted 20 times in Milli-Q water. LC-MS was performed using an Agilent 1100 Series LC (Agilent Technologies) coupled to a Bruker HCT-Ultra ion trap mass spectrometer (Bruker Daltonics). The LC-MS procedure was previously described (Takos et al., 2010). Extracted ion chromatograms for specific $[\mathrm{M}+\mathrm{Na}]^{+}$adduct ions, and their $\mathrm{MS}, \mathrm{MS}^{2}$ and retention times were used to identify the peaks. For absolute quantification of HNGs, quadratic calibration curves ranging from 0.4 to $100 \mu \mathrm{M}$ of lotaustralin, rhodiocyanoside $\mathrm{A}$ and linamarin were used. The peak areas were normalized with internal standard amygdalin $(190 \mu \mathrm{M})$.

\section{RNA extraction, cDNA synthesis and cloning of the full-length BGD3 cDNA sequence}

For preparation of RNA from L. japonicus flowers, early stages flowers were dissected into two parts: internal tissues (keel and reproductive organs) and external tissues (standard and wing). Tissues (3 g) were immediately frozen in liquid nitrogen and RNA extracted using a CTAB based protocol (Gambino et al., 2008). RNA was prepared from L. japonicus leaves $\left(100 \mathrm{mg}\right.$ ) using a Spectrum ${ }^{\mathrm{TM}}$ Plant Total RNA Kit (Sigma-Aldrich). Flower and leaf RNA was treated with RNAse-free DNaseI (QIAGEN) following the on-column digestion protocol of the Spectrum $^{\mathrm{TM}}$ Plant Total RNA Kit. First-strand cDNA was synthesized from 1-2 $\mu \mathrm{g}$ of total RNA using SuperScript ${ }^{\mathrm{TM}}$ III reverse transcriptase (Invitrogen) primed with $2.5 \mu \mathrm{M}$ oligo(dT) ${ }_{20}$.

The total RNA isolated from internal flower tissues (keel and reproductive organs) was used for 5' - and 3'-RACE PCR of the BGD3 cDNA using the FirstChoice RLM-RACE kit (Ambion). PCR reactions were performed with HotMaster $^{\mathrm{TM}} \mathrm{Taq}$ DNA polymerase (5 Prime $\mathrm{GmbH}$ ). Sequences of the gene specific PCR primers for RACE are shown in Table S1.

A full-length cDNA fragment encoding BGD3 was PCR amplified from the same cDNA used for 5'-RACE PCR using Phusion ${ }^{\mathrm{TM}}$ High-Fidelity DNA Polymerase (Finnzymes). The PCR product was cloned by Gateway® BP recombination reaction into the entry vector pDONR ${ }^{\text {TM}} 207$ (Invitrogen). Several clones were sequenced and the

cDNA sequence encoding BGD3 was lodged at the NCBI GenBank Nucleotide database (http://www.ncbi.nlm.nih.gov/genbank/) under the accession number JX982778. Sequences of the PCR primers, excluding attB1 and attB2 gateway cloning sites, are shown in Table S1.

\section{Quantitative Real-Time PCR}

Gene transcript levels of $B G D 2, B G D 4$ and $B G D 3$ were measured by Quantitative Real-Time PCR (RT-qPCR) on a Rotor-Gene Q instrument (QIAGEN). The gene encoding L. japonicus RNA polymerase II large subunit (GenBank accession AV777095) was used as a reference. The qPCR reactions $(20 \mu \mathrm{l})$ contained $400 \mathrm{nM}$ of each primer, $5 \mu \mathrm{l}$ of cDNA (diluted 1:10 in water) and 1x DyNAmo ${ }^{\mathrm{TM}}$ Flash SYBR ${ }^{\circledR}$ Green qPCR mix (Finnzymes). Thermocycling conditions were: denaturation at $95^{\circ} \mathrm{C}$ for $7 \mathrm{~min}$; amplification at $95^{\circ} \mathrm{C}$ for $15 \mathrm{~s}, 55^{\circ} \mathrm{C}$ for $30 \mathrm{~s}, 65^{\circ} \mathrm{C}$ for $30 \mathrm{~s}$, and final extension at $65^{\circ} \mathrm{C}$ for $5 \mathrm{~min}$. For each qPCR primer pair used, a single PCR product was obtained and its sequence verified. Normalized gene expression of target genes was obtained from the difference in cycle threshold of 
target genes and reference gene (RNA Pol II), taking into account primer efficiencies calculated from standard curves of diluted PCR product (Muller et al., 2002). Sequences of the qPCR primers are shown in Table S1.

\section{Transient expression of BGDs in leaves of Nicotiana benthamiana plants}

The $B G D 3$ cDNA sequence was sub-cloned by Gateway ${ }^{\circledR}$ LR recombination reaction from pDONR ${ }^{\mathrm{TM}} 207$ into the expression vector pJAM1502 (Luo et al., 2007). Constructs for expression of BGD2 and BGD4 from this vector have previously been reported (Takos et al., 2010). Overnight cultures of Agrobacterium tumefaciens (AGL1) containing the expression constructs for BGDs and the gene silencing inhibitor protein p19 (Voinnet et al., 2003) were grown and used for infiltration of $N$. benthamiana leaves essentially as previously described (Sparkes $e t$ al., 2006). After $4 \mathrm{~d}$ leaf discs $(1 \mathrm{~cm})$ were cut from infiltrated tissue, ground in $20 \mathrm{mM}$ MES buffer $(300 \mu \mathrm{l}), \mathrm{pH} 6.5$ containing $200 \mu \mathrm{M}$ of specified HNGs. Cyanogenesis from hydrolysis of $\alpha$-HNGs was detected with Feigl-Anger paper as described above. Hydrolysis of the non-cyanogenic $\gamma$-HNG, rhodiocyanoside A, was measured by LC-MS by taking samples $(25 \mu \mathrm{l})$ at the start and end of $30 \mathrm{~min}$ incubation.

\section{Homology modelling of BGD3}

Homology modelling and model quality validation of BGD2 and BGD4 using the crystal structure of the cyanogenic BGD from white clover (TrCBG) (Barrett et al., 1995) and the rice $\beta$-glucosidase OsBGlu12 (Sansenya et al., 2011) as a template has been performed as previously described using Modeller available at the Max Planck Institute for Developmental Biology (http://toolkit.tuebingen.mpg.de/hhpred) (Lai et al., 2014). The BGD3 sequence was modelled using the same TrCBG template (70\% amino acid sequence identity to BGD3) and the model was validated similarly. Additionally, a model was generated from the same template using the Swiss-Model on the EXPASY server (http://swissmodel.expasy.org). Both modelling approaches generated good quality models with similar quality statistics based on the ProQ validation parameters (Cristobal et al., 2001). The models generated by modeller and using the SWISS-MODEL approach converged and overlayed with a root mean square deviation of $0.18 \AA$, which justified using the models to probe active site architecture.

\section{Nectar sampling}

Nectar samples were collected by pipetting of autoclaved Milli-Q water $(50 \mu \mathrm{l})$ inside $L$. japonicus flowers and removing the water from the base of the flowers with the same tip, essentially as a previously described method for low nectar volumes (Morrant et al., 2009). Samples were then directly analyzed, without dilution, by LC-MS as described above. For extraction of neolinustatin, $4 \mathrm{~g}$ of flax seeds (L. usitatissimum) were ground to powder in liquid nitrogen and extracted in $8 \mathrm{ml}$ of $85 \%$ (v/v) $\mathrm{MeOH}$ as described above. A $50 \mu \mathrm{l}$ aliquot of the extract was evaporated under vacuum and resuspended in $50 \mu 1$ Milli-Q water. For the co-elution analysis, this flax seed extract aliquot was diluted 1:10 in the nectar sample, and also 1:10 in water to serve as a control sample containing the same amount of neolinustatin. Both samples were analyzed by LC-MS as described above. 


\section{RESULTS}

\section{Genetic analysis of cyanogenesis from flowers}

Biosynthetic and BGD cyd mutants previously obtained from the forward genetic screen of L. japonicus leaf tissue (Takos et al., 2010) were analyzed to determine if the same genes are required for cyanogenesis in flower tissues. To qualitatively assess cyanogenesis we used the HCN sensitive paper developed by Feigl and Anger (Feigl and Anger, 1966). Cyanogenesis is detected from both apical leaves and mature flowers of wild type L. japonicus plants (accession MG20) (Fig. 1a). The cyd2-2 mutant contains an intron splice site mutation that results in mis-splicing of the $B G D 2$ gene transcript and no functional expression of the enzyme. While apical leaves of the cyd2-2 mutant are acyanogenic the mature flowers retained comparable cyanogenesis to wild type plants, indicating that a different cyanogenic BGD is present in flowers.

The cydl mutant contains a partial deletion of the CYP79D3 gene, encoding the cytochrome P450 that catalyzes the first committed step in the biosynthesis of both cyanogenic $\alpha$-HNGs, lotaustralin and linamarin, and the noncyanogenic $\gamma$ - and $\beta$-HNGs, rhodiocyanoside A and D (Takos et al., 2011). Apical leaves and mature flowers of the cydl mutant are acyanogenic and all classes of HNGs were confirmed by LC-MS to be essentially absent in flowers, while the cyd2-2 mutant plants have unaltered levels of HNGs in flowers (Fig. 1b). Therefore CYP79D3 is responsible for biosynthesis of HNGs in both leaves and flowers.

The cyd4 mutant contains an R366 to K366 change in the EXXR motif of the cytochrome P450 CYP736A2 that is specific for the biosynthesis of $\alpha$-HNGs in leaf tissue (Takos et al., 2011); the motif is present in essentially all cytochrome P450s and is required for correct protein folding (Hasemann et al., 1995). Apical leaves and mature flowers of cyd4 are less cyanogenic than wild type plants (Fig. 1a) and LC-MS analysis confirmed the specific reduction of cyanogenic $\alpha$-HNGs (Fig. 1b). Therefore CYP736A2 catalyses the second step in the pathway for biosynthesis of the majority of $\alpha$-HNGs in both leaves and flowers. The remaining $\alpha$-HNG biosynthesis may be attributed to an unidentified cytochrome P450 enzyme that is most active for catalysis of the second step of rhodiocyanoside biosynthesis (Takos et al., 2011; Saito et al., 2012).

\section{Developmental timing and tissue specificity of cyanogensis}

The Feigl-Anger paper was used to assess the developmental timing and the spatial distribution of cyanogenesis in flowers. Hydrogen cyanide release is detected from early flowers and in mature flowers but not detected at the bud stage or from pods (Fig. 2a). In mature flowers the keel and the enclosed reproductive organs are cyanogenic while the sepal, standard and wing structures are not (Fig. 2b).

While not all flower tissues are cyanogenic, LC-MS analysis confirms that each of the flower tissues contains a similar profile of HNGs (Fig. 2c). Similarly, while buds and pods are acyanogenic, they also contained HNGs (Fig. S1.). The standard, keel and wing structures contain more than double the concentration of HNGs per mg fresh weight than apical leaf tissue, while the sepal and reproductive organs have quantities more similar to leaf tissues. The presence of $\alpha$-HNGs in the acyanogenic tissues (the sepal, standard and wing), and at the acyanogenic 
developmental stages (buds and pods), indicates the absence or inhibition of a cyanogenic BGD activity in these tissues/developemental stages.

\section{Identification and cloning of a candidate flower-specific cyanogenic BGD}

To identify candidate genes encoding the cyanogenic BGD in L. japonicus flowers, the BGD2 cDNA sequence was used for a BLASTN search of all clones and contigs in the KAZUSA Assembly 1.0 of the L. japonicus genome sequence. Two overlapping DNA fragments, LjSGA_084211 and LjSGA_032385 were identified as encoding part of a BGD with a deduced amino acid sequence similar to BGD2. These fragments spanned the region encoding the substrate binding cavity and contained a glycine amino acid at the corresponding position to G211 of BGD2. This residue was previously shown to be critical for the acceptance of lotaustralin and linamarin as substrates by BGD2, which suggested the ability of this candidate gene to hydrolyse $\alpha$-HNGs (Lai et al., 2014).

The corresponding 5' and 3' cDNA ends of the LjSGA_032385.1 and LjSGA_084211.1 fragments were obtained by RACE PCR from RNA isolated from flowers. A full-length cDNA fragment was then amplified and cloned and the deduced 515 amino acid protein sequence obtained was called BGD3. An alignment of BGD3, 2 and 4 shows the high amino acid sequence identity across the full-length protein sequences (Fig. 3). The G209 of BGD3 is at the equivalent position of the active site as the critical residue G211 in BGD2 and is indicated by a red box, in BGD4 this residue is V211. The conserved glutamic acids E206 and E420 (BGD3 numbering) which have respective roles as acid/base catalyst and nucleophile are indicated by red arrows (Withers et al., 1990; Wang et al., 1995).

\section{Quantitative Real-Time PCR analysis of $B G D$ gene expression}

The tissue-specific accumulation of $B G D 3$ gene transcripts was determined by RT-qPCR. The $B G D 3$ gene transcripts were detected in the internal cyanogenic flower tissues but not in the external non-cyanogenic tissues (Fig. 4a) nor in leaves (Fig. 4b). The association of BGD3 gene transcript accumulation with cyanogenic flower tissues (keel and reproductive organs) is consistent with a role as the flower specific cyanogenic BGD and the absence of these transcripts in the external flower tissues (standard and wing) would explain why these tissues are acyanogenic despite containing lotaustralin and linamarin (Fig. 2b and c). Conversely, BGD2 gene transcripts were detected in leaves but not flowers and this is consistent with the observation that leaves of the $c y d 2-2$ mutant are acyanogenic (Fig. 1a). Transcripts of the BGD4 gene were detected in both flower tissues and leaves, and do not correlate with cyanogenesis, as is expected from the previously assigned role of BGD4 in catabolism of noncyanogenic HNGs (Takos et al., 2010; Lai et al., 2014).

\section{Enzymatic activity of BGDs transiently expressed in tobacco plants}

To determine if BGD3 could hydrolyse cyanogenic $\alpha$-HNG and/or non-cyanogenic $\gamma$-HNG substrates, the BGD3 enzyme was transiently expressed in $N$. benthamiana leaves by Agrobacterium infiltration. For comparative purposes the BGD2 and BGD4 enzymes were also transiently expressed. Leaf discs excised from transformed leaves were macerated and mixed with substrates and the hydrolysis of the cyanogenic $\alpha$-HNGs was measured by Feigl-Anger paper, and of the non-cyanogenic $\gamma$-HNG rhodiocyanoside A, it was measured by LC-MS. 
Cyanogenesis was detected from each of the BGD expressing leaf discs when incubated with the exogenous substrate prunasin (Fig. 5a). Prunasin, the $\alpha$-HNG from almond, harbors a planar benzene ring molecular structure, which can be accommodated into the substrate binding pocket of the L. japonicus BGD isoforms (Lai et al., 2014) and so its hydrolysis by each of the BGDs indicates functional enzyme expression. Cyanogenesis was detected for both BGD3 and BGD2 expressing leaf discs when incubated with the endogenous $\alpha$-HNGs lotaustralin and linamarin, but not for BGD4. Each of the BGDs were able to hydrolyse rhodiocyanoside A as indicated by the reduction to between 0 to $20 \%$ of the starting level of substrate after 30 min of incubation with leaf discs (Fig. 5b).

Leaf discs expressing only the p19 protein did not hydrolyse the $\alpha$-HNGs lotaustralin and linamarin or rhodiocyanoside A. From these results BGD3 is thus assigned as the cyanogenic BGD of L. japonicus flowers able to hydrolyse all endogenous HNGs.

\section{Molecular modelling of substrate binding pockets of BGDs}

The molecular modelling of BGD2 and BGD4, based upon crystal structures of the cyanogenic $\beta$-glucosidase from white clover (TrCBG) (Barrett et al., 1995) and the rice $\beta$-glucosidase OsBGlu12 (Sansenya et al., 2011), showed that the G211 residue in BGD2, compared to a valine residue in the equivalent position in BGD4, increases the space available in the substrate binding cavity to accommodate the $\alpha$-HNG substrates lotaustralin and linamarin (Lai et al., 2014). These have a bulkier three dimensional structure compared to prunasin or the $\gamma$-HNG rhodiocyanoside A. In this study, a homology model of BGD3 was generated using the structure of the TrCBG as a template. The high sequence identity of BGD3 to both the template as well as to BGD2 and BGD4 from L. japonicus (Fig. 3) renders comparative modelling a viable tool to compare the active site architectures of these enzymes. The amino acid residues mediating the recognition of the glycone moiety common to the substrates of all three enzymes (substrate binding subsite -1) are strictly conserved. The conservation is also valid for the catalytic acid/base and nucleophile (E206 and E420 respectively), which is reflected by the excellent overlay of these residues in the models of BGD2, BGD3 and BGD4 (Fig. S2a). The only large difference is observed at the position of G209 (BGD3 numbering) flanking the active site area above the glycone binding site, where a glycine is also present in the cyanogenic BGD2 enzyme, whereas a valine (V211) is present in the acyanogenic BGD4 at this position. The presence of a glycine at this position provides the necessary space for the binding of the relatively bulky $\alpha$-HNG substrates in both BGD3 and BGD2, which have a similarly sized aglycone binding pocket in the generated homology models (data not shown). By contrast, the bulky side chain of V211 in BGD4 protrudes into the aglycone binding pocket narrowing the space available for substrates at this position, as observed by comparing the models of BGD3 and BGD4 (Fig. $\mathrm{S} 2 \mathrm{~b}$ and $\mathrm{c}$ ). These modelling results provide a structural rationale for observed specificity of BGD3 and highlight the structural role of the absence of a side chain of the G209 in BGD3 as an essential feature that governs the cyanogenic activity of this BGD enzyme.

\section{Natural variation in cyanogenesis of $L$. japonicus flowers}

Obtaining plants with loss of function mutations in the $B G D 3$ gene would provide genetic verification that it is the cyanogenic BGD of flowers. We tested tissues from 29 natural accessions of L. japonicus for cyanogenesis using

Feigl-Anger paper (Table S2) and identified three accessions that showed cyanogenesis in leaves but were 
acyanogenic in flowers: MG3, MG53 and MG76 (Fig. 6). All three accessions originate from the southern half of Honshu, the main island of Japan. LC-MS analysis confirmed that flowers and leaves of each of the three accessions contained $\alpha$-HNGs (Fig. S3), suggesting a flower specific defect in hydrolysis of HNGs. We amplified the full-length cDNA sequence of the $B G D 3$ gene from each of these accessions and in each case a nucleotide deletion introduces a frameshift resulting in a premature stop codon at position 415 of the deduced amino acid sequence (AAC CCT CTA ATC to AAC CTC TAA TC). This stopcodon is just before the I/VTENG motif, which is highly conserved in all family 1 glycosyl hydrolases, as the glutamic acid residue (E420) acts as an attacking nucleophile in the reaction mechanism (Withers et al., 1990) and so this truncation of the protein would result in a loss of enzyme activity. These accessions therefore demonstrate genetically that BGD3 is the cyanogenic BGD of flowers.

\section{Hydroxynitrile glucosides and diglycosides in flower nectar}

Flowers attract insect pollinators by providing rewards such as nectar. Reports of the presence of defence metabolites in nectar include the occurrence of the cyanogenic diglucoside amygdalin in almonds (London-Shafir et al., 2003). Nectar was washed from L. japonicus flowers with water and analyzed by LC-MS to determine if hydroxynitrile glucoside species were present. The $\alpha-, \beta$-, and $\gamma$-HNG species that are found in flowers (Fig. 1b) are also present in nectar (Fig. 7a). In addition, specific to nectar, are two hydroxynitrile diglycoside (HNdG) species that were predicted to be diglycosides of the lotaustralin aglycone (peak 5, green, $[\mathrm{M}+\mathrm{Na}]^{+}=446$ ), and the rhodiocyanoside A/D aglycones (peak 3, brown, $[\mathrm{M}+\mathrm{Na}]^{+}=444$ ) based upon fragmentation patterns of MS2 spectra (Fig. S4). All of these compounds are estimated to be present at less than $5 \%$ of the quantity found in flower tissues (estimated from LC-MS traces from whole flowers), but their low levels makes precise quantitation difficult. Since flax seeds ( $L$. usitatissimum) contains neolinustatin, the 6'-O-glucoside of lotaustralin (Smith et al., 1980), nectar was spiked with flax seeds extract to determine if the Lotus HNdG species (peak 5) was neolinustatin. Neolinustatin has the same $\mathrm{m} / \mathrm{z}$ and MS2 fragmentation as the L. japonicus HNdG species represented by peak 5 (Fig. S4), but the two compounds do not co-elute (Fig. 7a). The retention time of neolinustatin was unaltered when flax seeds extract was analyzed separately. This suggests the L. japonicus $\mathrm{HNdG}$ of $\mathrm{m} / \mathrm{z} 446$ contains either different hexose units or a different glycosidic linkage between the two sugar moieties.

To assess the hydrolysis of the different HNG and HNdG compounds by BGDs, flowers were macerated in order to mix these two components and the time course hydrolysis of compounds was measured by LC-MS. Following $4 \mathrm{~h}$ incubation, the residual amounts of lotaustralin, rhodiocyanoside A and linamarin present correspond to $25 \%, 40 \%$ and $70 \%$ of the initial amounts respectively (Fig. 7b). The two HNdG species were not significantly hydrolysed indicating there is not a BGD present in flowers that is active with these diglycosidic compounds. 


\section{DISCUSSION}

Plants face a greater challenge in the defense of floral tissues than foliar tissues as they must balance the deterrence of florivores against the need to attract pollinators at the same time as more efficient defense of floral tissues is tightly linked to reproductive success (Irwin et al., 2004; Adler et al., 2012). The $\alpha$-HNGs are known to be present as part of the defense of foliar tissues in over 3,000 plant species across the plant kingdom (Møller, 2010; Gleadow and Møller, 2014), yet there are few detailed studies of this defense in flowers. The higher level of HNGs accumulated in L. japonicus floral tissues compared to foliar tissues, suggests these compounds also have an important role in deterrence of florivory and is consistent with 'optimal defense theory' in allocating resources in accordance to the fitness value of plant tissues (Ohnmeiss and Baldwin, 2000). The cyanogenesis defense provides an ideal immediate response to florivores and primary nectar robbers. There are many other examples of high content of defense compounds in flowers, including such classes of metabolites as glucosinolates (Straus et al., 2004), cyclic hydroxamic acids (Bravo and Copaja, 2002), terpenoids (Tawaha and Hudaib, 2012), flavonoids (Gruber et al., 2008) and alkaloids (Eichhorn et al., 1998). While a meta-analysis of published and unpublished studies did not support the 'optimal defense theory' for defense of flowers by secondary metabolites (McCall and Fordyce, 2010), the survey results may be obscured by alternative defense strategies such as indirect defenses, mechanical defenses and inducible defenses and so must be evaluated carefully on a case by case basis (Irwin et al., 2004).

The BGD3 enzyme responsible for hydrolysis of $\alpha$-HNGs and subsequent release of hydrogen cyanide from $L$. japonicus flowers identified in this study joins two other HNG hydrolysing BGDs which have been characterized in L. japonicus; i) the leaf expressed BGD2 which can hydrolyse cyanogenic and non-cyanogenic HNGs, ii) the leaf and flower expressed BGD4 which can hydrolyse only non-cyanogenic $\gamma$ - and $\beta$-HNGs (Lai et al., 2014). The presence of a flower specific cyanogenic BGD was suggested because cyd2-2 mutants, which have acyanogenic leaves due to loss of a functional BGD2 enzyme, retain cyanogenesis in flowers. The cloning of a full-length cDNA encoding a candidate flower specific BGD was based upon partial BGD gene sequences in the L. japonicus genome selected because they contained the critical glycine residue required for hydrolysis of $\alpha$-HNGs by BGD2 (Lai et al., 2014). Whereas all floral tissues contain HNGs only tissues which express BGD3 gene transcripts are cyanogenic. $L$. japonicus accessions with acyanogenic flowers contain a non-functional $B G D 3$ gene due to an identical nucleotide deletion resulting in a frame-shift and early stop-codon. The identical nature of the mutation suggests a single origin of the mutated gene, although the geographical distance between the sites of collection, particularly for MG3 in relation to MG53 and MG76, is still considerable, as is their year of collection (Table S2). Similar HNG hydrolysis systems therefore exist in L. japonicus flowers and leaves where BGD3 and BGD2 respectively have broader substrate specificity for, in addition to the $\gamma$ - and $\beta$-HNGs, the $\alpha$-HNGs for release of hydrogen cyanide from these tissues, whereas BGD4 is expressed in both tissue types and has restricted substrate specificity to $\gamma$ - and $\beta$-HNGs.

It is intriguing that BGD3 is specifically expressed in the internal tissues of flowers (keel and reproductive organs) rather than the cyanogenic BGD2 having a continued expression throughout the plant. Given the common developmental lineage of petals and sepals with leaves, this suggests a selective advantage (Gutierrez-Cortines and Davies, 2000). A possible explanation for the highly specialised spatial expression of two separate cyanogenic BGDs 
could be that a more general expression of a cyanogenic BGD, to include the large standard petal and the two wings, more easily results in the accidental release of hydrogen cyanide due to minor structural damage. As a consequence, legitimate pollinators may perceive such flowers as damaged, and this could reduce pollinator visits. Maintaining cyanogenic defences in the internal floral structures essential for reproduction could be a trade-off between attracting pollinators and deterring herbivores. The relative high expression of BGD4 in all tissues is remarkable. As was reported by Lai et al. (2014), this gene is thought to have more recently evolved by substrate specialization for rhodiocyanosides finding its basis in a promiscuous activity of a progenitor cyanogenic $\beta$-glucosidase. High expression levels are suggested to compensate for weak promiscuous activities during the evolutionary emergence of alternative enzymatic functions (Khersonsky and Tawfik, 2010).

Nectar thieves, often ants, do not damage floral tissues but acquire nectar through the floral opening used by legitimate pollinators and thereby reduce visitation by pollinators or threaten incoming pollinators (Lach, 2008; Ballantyne and Willmer, 2012). Ants may also secrete antibiotic substances that degrade pollen viability (Wagner, 2000). Nectar containing secondary metabolites, known as toxic nectar, has long been proposed to repell ants from flowers (Janzen, 1977), although this has been contested by several studies (Haber et al., 1981; Guerrant and Fiedler, 1981). The deterrence of ants has been extended to nectar robbers, for example the iridoid glycosides in nectar of Catalpa speciosa which deter the moth larvae Ceratomia catalpae (Stephenson, 1982) and the alkaloids gelsimine and nicotine which deter the carpenter bee Xylocopa virginica in Gelsemium sempervirens and Nicotiana attenuate, respectively (Adler and Irwin, 2005; Kessler et al., 2008). The $\alpha$-HNGs in L. japonicus nectar may also provide an effective defense against nectar thieves, as ants are deterred by caterpillar secretions containing cyanogenic compounds (Darling et al., 2001). Yet bees, the primary pollinator of Lotus flowers (Pellissier et al., 2013), can tolerate $\alpha$-HNGs in the nectar of almond flowers, although they may show preferences for other nectar dependent upon competing nearby flowering plants (London-Shafir et al., 2003). It has been proposed that nectar secondary metabolites can indeed be utilized by bees to reduce pathogen infections (Manson et al., 2010). The presence of HNGs in nectar may also deter growth of microbes in situ, which can be introduced by the pollinating bees, to the sugar rich environment (Aizenberg-Gershtein et al., 2013). In this context the presence of rhodiocyanoside A and its proposed conversion to a toxic furanone compound (Saito et al., 2012) may be important in reducing fungal growth.

Two HNdG species with MS2 fragmentation patterns corresponding to the glycosylated form of rhodiocyanoside A/D and lotaustralin were detected in nectar. None of the compounds are structurally identical to neolinustatin found in flax seeds (Smith et al., 1980). The biological significance of HNdG species in nectar is unclear and their presence has only previously been reported for the $\alpha-\mathrm{HNdG}$ amygdalin in almond nectar (London-Shafir et al., 2003). Several HNdG species, have also been found in the flowers of Eucalyptus, although it is unknown if these are present in nectar (Neilson et al., 2011). Vicianin Hydrolase gene transcripts, encoding a cyanogenic BGD not closely related to the Lotus enzymes that hydrolyses the HNdG vicianin, have been detected in flowers of Vicia angustifolia, but the presence of vicianin in nectar was not reported, (Ahn et al., 2007). The HNdG linustatin has been reported in Hevea brasiliensis and proposed to serves as a transport form for $\alpha$-HNGs enabling their mobilization from endosperm to seedlings where they are metabolized to non-cyanogenic compounds to liberate reduced nitrogen to support seedling growth (Selmar et al., 1988). In the case of L. japonicus floral nectar it is unlikely the HNdGs are simply a means of 
transport from producing cells to the nectar as HNG species found in nectar do not seem to arise from the HNdG species, which were very stable in the hydrolysis assay. This transport system would also not be in accordance with the loading of nectar observed in other Fabaceae plant species, which collapse cells, releasing their contents through the pores of guard cells (Horner et al., 2003). Possibly the HNdG species represent a more stable chemical defense against florivores, nectar thieves or even microorgamisms than the HNG species, but this would require a BGD in these organisms to bioactivate the compounds as our study indicates that there is no BGD capable of hydrolysing the HNdGs in L. japonicus flowers.

Genetic tools such as mutant lines, combined with field work can provide a sophisticated approach to study the ecological challenges plants face to attract pollinators whilst deterring florivores (Kessler and Baldwin, 2011), and for this L. japonicus is an ideal system to experimentally address some of issues raised above. For example are secondary metabolites in nectar present for a number of different reasons (Møller, 2010) or as a deterrance of ants? The broad spectrum of hydrogen cyanide toxicity against most organisms would suggest $\alpha$-HNGs represent a constitutive and an immediate defense against florivores, nectar robbers and thieves. This may incur resource costs (e.g. metabolic energy) and ecological costs (e.g. deterrence of mutualists), which are a trade-off to defense (Neilson et al., 2013). The genetic resources of L. japonicus, which include natural accessions with loss of function of BGD3, loss of function mutants of BGD2 and BGD4 (Lai et al., 2014), and cyd mutants that are deficient in HNG biosynthesis (Takos et al., 2010; Takos et al., 2011) can be used to assess the contribution of each of the HNG species and their bioactivating BGDs to defense. The costs of this defense in flowers can thus be determined.

\section{ACKNOWLEDGEMENTS}

This work was supported by the Danish Council for Independent Research - Natural Sciences and by the VILLUM Research Center for Plant Plasticity.

\section{SUPPLEMENTARY DATA}

Fig. S1 HNG content of L. japonicus MG20 flowers at different developmental stages. Extracted ion chromatogram peaks from LC-MS showing HNG species in flowers at bud, early flower, mature flower, and pod, corresponding to photos in Fig. 2a, are linamarin (light-blue, m/z 270), rhodiocyanosides D and A (red, m/z 282) and lotaustralin (dark-blue, m/z 284) as also indicated in Fig. 1 b.

Fig. S2 Active site architecture of the Lotus $\beta$-glucosidase isozymes BGD2, BGD3, and BGD4 modelled on TrCBG, the cyanogenic $\beta$-glucosidase from white clover (Barrett et al., 1995). (a) Superimposition of catalytic residues and those flanking the putative aglycone part of the active site cleft. The position of 2-deoxy-2-fluoroglucose (G2F) from the rice $\beta$-glucosidase Os4BGlu12 crystal structure (Sansenya et al., 2011) is shown to depict the glycone binding and the carbon 1 atom $(\mathrm{C} 1)$ of the glucose is labelled. The amino acid numbering of the BGD3 isozyme is shown and 
the catalytic nucleophile (E420) and catalytic acid/base (E206) are perfectly superimposed in the three isozymes. The only large difference in the active site cleft flanking the putative aglycone binding site is the substitution of G209 in BGD3 (in BGD2, G211) to a valine in BGD4 (V211). (b) and (c) Topological details of the active sites of the BGD3 and the BGD4 isozymes, respectively. The surface is colored red to visualize the position of the catalytic nucleophile in both enzymes, whereas the specificity determinant G209 in BGD3 and V211 in BGD4 are khaki colored.

Fig. S3 HNG content of L. japonicus mature flowers and apical leaves from natural accessions. Extracted ion chromatogram peaks from LC-MS showing HNG species in mature flowers and apical leaves of accessions MG3, MG53 and MG76 are linamarin (light-blue, m/z 270), rhodiocyanosides D and A (red, m/z 282) and lotaustralin (dark-blue, m/z 284) as also indicated in Fig. 1b. The accession MG53 does not biosynthesize rhodiocyanosides.

Fig. S4 MS and MS2 spectra of HNdGs in L. japonicus MG20 nectar and in flax seeds extract. Fragmentation of the diglycoside of the rhodiocyanoside A/D aglycones $\left([\mathrm{M}+\mathrm{Na}]^{+}=444\right)$ provided peaks at $282 \mathrm{~m} / \mathrm{z}$ (corresponding to $[\mathrm{M}+\mathrm{Na}]^{+}$of rhodiocyanoside A/D monoglycosides) and $347 \mathrm{~m} / \mathrm{z}$ (corresponding to [Hexose $\left.+\mathrm{Hexose}-\mathrm{H}_{2} \mathrm{O}+\mathrm{Na}\right]^{+}$) Fragmentation of the diglycoside of the lotaustralin aglycone $\left([\mathrm{M}+\mathrm{Na}]^{+}=446\right)$ provided peaks of $419 \mathrm{~m} / \mathrm{z}$ (corresponding to the loss of HCN from the parent ion), $374 \mathrm{~m} / \mathrm{z}$ (which could correspond to [Hexose+Hexose$\left.\mathrm{H}_{2} \mathrm{O}+\mathrm{HCN}+\mathrm{Na}\right]^{+}$) and $347 \mathrm{~m} / \mathrm{z}$ (corresponding to $\left[\text { Hexose }+\mathrm{Hexose}-\mathrm{H}_{2} \mathrm{O}+\mathrm{Na}\right]^{+}$) . The same fragmentation pattern as for the diglycoside of the lotaustralin aglycone from $L$. japonicus was observed for neolinustatin $\left([\mathrm{M}+\mathrm{Na}]^{+}=446\right)$ from flax seeds.

Table S1 PCR primers used in this study

Table S2 Detection of cyanogenesis from mature flowers of $L$. japonicus natural accessions. Cyanogenesis was detected by Feigl-Anger paper as described in methods. The three natural accessions with acyanogenic flowers are written in bold and with the table row shaded.

\section{COMPLIANCE WITH ETHICAL STANDARDS}

Conflict of interest: The authors declare that they have no conflicts of interest.

Ethical standards: There are no ethical considerations in this work. 


\section{REFERENCES}

Adler LS, Irwin RE (2005) Ecological costs and benefits of defenses in nectar. Ecology 86:2968-2978

Adler LS, Seifert MG, Wink M, Morse GE (2012) Reliance on pollinators predicts defensive chemistry across tobacco species. Ecol Lett 15:1140-1148

Ahn YO, Saino H, Mitztani M, Shimizu B, Sakata K (2007) Vicianin hydrolase is a novel cyanogenic $\beta$-glycosidase specific to $\beta$-vicianoside (6-O- $\alpha$-arabinopyranosyl- $\beta$-D-glucopyranoside) in seeds of Vicia angustifolia. Plant Cell Physiol 48:938-947

Aizenberg-Gershtein Y, Izhaki I, Halpern M (2013) Do honeybees shape the bacterial community composition in floral nectar? PLOS ONE 8:e67556

Ballantyne G, Willmer P (2012) Nectar theft and floral ant-repellence: a link between nectar volume and antrepellent traits? PLOS ONE 7:e43869

Bak S, Paquette SM, Morant M, Morant AV, Saito S, Bjarnholt N, Zagrobelny M, Jørgensen K, Osmani S, Simonsen HT, Sánchez-Pérez R, van Heeswijck TB, Jørgensen B, Møller BL (2006) Cyanogenic glycosides: a case study for evolution and application of cytochromes P450. Phytochem Rev 5:309-329

Barrett T, Suresh CG, Tolley SP, Dodson EJ, Hughes MA (1995) The crystal structure of a cyanogenic $\beta$-glucosidase from white clover, a family 1 glycosyl hydrolase. Structure 3:951-960

Bjarnholt N, Rook F, Motawia MS, Cornett C, Jørgensen C, Olsen CE, Jaroszewski JW, Bak S, Møller BL (2008) Diversification of an ancient theme: hydroxynitrile glucosides. Phytochemistry 69:1507-1516

Blomstedt CK, Gleadow RM, O’Donnell N, Naur P, Jensen K, Laursen T, Olsen CE, Stuart P, Hamil JD, Møller BL, Neale AD (2012) A combined biochemical screen and TILLING approach identifies mutations in Sorghum bicolor L. Moench resulting in acyanogenic forage production. Plant Biotechnol J 10:54-66

Bravo HR, Copaja SV (2002) Contents and morphological distribution of 2,4-dihydroxy-1,4-benzoxazin-3-one and 2-benzoxazoline in Acanthus mollis in relation to protection from larvae of Pseudaletia impuncta. Ann Appl Biol 140:129-132

Conn EE (1981) Cyanogenic glycosides. In: Conn EE (ed) The biochemistry of plants. Academic Press, New York, pp 479-499

Cristobal S, Zemla A, Fischer D, Rychlewski L, Elofsson A (2001) A study of quality measures for protein threading models. BMC bioinformatics 2:5 
Darling DC, Schroeder FC, Meinwald J, Eisner M, Eisner T (2001) Production of a cyanogenic secretion by a thyridid caterpillar (Calindoea trifascialis, Thyrididae, Lepidoptera). Naturwissenschaften 88:306-309

Eichhorn J, Takada T, Kita Y, Zenk MH (1998) Biosynthesis of the amaryllidaceae alkaloid galanthamine. Phytochemistry 49:1037-1047

Feigl F, Anger V (1966) Replacement of benzidine by copper ethylacetoacetate and tetra base as spot-test reagent for hydrogen cyanide and cyanogen. Analyst 91:282-284

Foo LY, Lu Y, Molan AL, Woodfield DR, McNabb WC (2000) The phenols and prodelphinidins of white clover flowers. Phytochemistry 54:539-548

Forslund K, Morant M, Jørgensen B, Olsen CE, Asamizu E, Sato S, Tabata S, Bak S (2004) Biosynthesis of the nitrile glucosides rhodiocyanoside $\mathrm{A}$ and $\mathrm{D}$ and the cyanogenic glucosides lotaustralin and linamarin in Lotus japonicus. Plant Physiol 135:71-84

Gambino G, Perrone I, Gribaudo I (2008) A rapid and effective method for RNA extraction from different tissues of grapevine and other woody plants. Phytochem Analysis 19:520-525

Gleadow RM, Møller BL (2014) Cyanogenic glycosides: synthesis, physiology, and phenotypic plasticity. Ann Rev Plant Biol 65:155-185

Gruber M, Skadhauge B, Yu M, Muir A, Richards K (2008) Variation in morphoplogy, plant habit, proanthocyanidins, and flavonoids within a Lotus germplasm collection. Can J Plant Sci 88:121-132

Gruhnert C, Biehl B, Selmar D (1994) Compartmentation of cyanogenic glucosides and their degrading enzymes. Planta 195:36-42

Guerrant EO, Fiedler PL (1981) Flower defenses against nectar-pilferage by ants. Biotropica 13:S25-33

Gutierrez-Cortines ME, Davis, B (2000) Beyond the ABCs: ternary complex formation in the control of floral organ identity. Trends Plant Sci 5:471-476

Haber WA, Frankie GW, Baker HG, Baker I, Koptur S (1981) Ants like flower nectar. Biotropica 13:211-214

Harper NL, Cooper-Driver GA, Swain T (1976) A survey for cyanogenesis in ferns and gymnosperms. Phytochemistry 15:1764-1767

Hasemann CA, Kurumbail RG, Boddupalli SS, Peterson JA, Deisenhofer J (1995) Structure and function of cytochromes P450: a comparative analysis of three crystal structures. Structure 2:41-62

Heil M (2011) Nectar: generation, regulation and ecological functions. Trends Plant Sci 16:191-200 
Horner HT, Healy RA, Cervantes-Martinez T, Palmer RG (2003) Floral nectary structure and development in Glycine max L. (Fabaceae). Int J Plant Sci 164:675-690

Hughes MA, Brown K, Pancoro A, Stuart Murray B, Oxtoby E, Hughes J (1992) A molecular and biochemical analysis of the cyanogenic $\beta$-glucosidase (Linamarase) from Cassava (Manihot esculenta Cranz). Arch Biochem Biophys 295:273-279

Irwin RE, Adler LS, Brody AK (2004) The dual role of floral traits: pollinator attraction and plant defense. Ecology $85: 1503-1511$

Irwin RE, Bronstein JL, Manson JS, Richardson L (2010) Nectar robbing: ecological and evolutionary perspectives. Ann Rev Ecol Evol S 41:271-292

Janzen DH (1977) Why don’t ants visit flowers? Biotropica 9:252

Jones DA (1998) Why are so many food plants cyanogenic? Phytochemistry 47:155-162

Jørgensen K, Bak S, Busk PK, Sørensen C, Olsen CE, Puonti-Kaerlas J, Møller BL (2005) Cassava plants with a depleted cyanogenic glucoside content in leaves and tubers: distribution of cyanogenic glucosides, their site of synthesis and transport, and blockage of the biosynthesis by RNA interference technology. Plant Physiol 139:363374

Kessler D, Gase K, Baldwin IT (2008) Field experiments with transformed plants reveal the sense of floral scents. Science 321:1200-1202

Kessler D, Baldwin IT (2011) Back to the past for pollination biology. Curr Opin Plant Biol 14:429-434

Khersonsky O, Tawfik, DS (2010) Enzyme promiscuity: a mechanistic and evolutionary perspective. Annu Rev Biochem 79: 471-505

Krupnick GA, Weis, AE, Campbell, DR (1999) The consequences of floral herbivory for pollinator service to Isomeris arborea. Ecology 80:125-134

Lach L (2008) Argentine ants displace floral arthropods in a biodiversity hotspot. Divers Distrib 14:281-290

Lai D, Hachem MA, Robson F, Olsen CE, Wang TL, Møller BL, Takos AM, Rook F (2014) The evolutionary appearance of non-cyanogenic hydroxynitrile glucosides in the Lotus genus is accompanied by the substrate specialization of paralogous $\beta$-glucosidases resulting from a crucial amino acid substitution. Plant J 79:299-311

Lamont BB (1994) Injury-induced cyanogenesis in vegetative and reproductive parts of two Grevillea species and their F1 hybrid. Ann Bot-London 71:537-542

Lewis CE, Zona S (2000) A survey of cyanogenesis in palms (Arecaceae). Biochem Syst Ecol 28:219-228 
London-Shafir I, Shafir S, Eisikowitch D (2003) Amygdalin in almond nectar and pollen - facts and possible roles. Plant Syst Evol 238:87-95

Luo J, Nishiyama Y, Fuell C, Taguchi G, Elliott K, Hill L, Tanaka Y, Kitayama M, Yamazaki M, Bailey P, Parr A, Michael AJ, Saito K, Martin C (2007) Convergent evolution in the BAHD family of acyl transferases: identification and characterization of anthocyanin acyl transferases from Arabidopsis thaliana. Plant J 49:810-828

Manson JS, Otterstatter MC, Thomson JD (2010) Consumption of a nectar alkaloid reduces pathogen load in bumble bees. Oecologica 162:81-89

McCall AC, Karban R (2006) Induced defense in Nicotiana attenuate (Solanaceae) fruit and flowers. Oceologia $146: 566-571$

McCall AC, Irwin RE (2006) Florivory: the intersection of pollination and herbivory. Ecol Lett 9:1351-1365

McCall AC, Fordyce JA (2010) Can optimal defence theory be used to predict the distribution of plant chemical defences? J Ecol 98:985-992

Miller RE, Jensen R, Woodrow IE (2006) Frequency of cyanogenesis in tropical rainforests of Far North Queensland, Australia. Ann Bot-London 97:1017-1044

Miller RE, Tuck KL (2013) Reports on the distribution of aromatic cyanogenic glycosides in Australian tropical rainforest tree species of the Lauraceae and Sapindaceae. Phytochemistry 92:146-152

Morant AV, Jørgensen K, Jørgensen C, Paquette SM, Sánchez-Pérez R, Møller BL, Bak S (2008) $\beta$-Glucosidases as detonators of plant chemical defense. Phytochemistry 69:1795-1813

Morrant DS, Schumann R, Petit S (2009) Field methods for sampling nectar from flowers with low nectar volumes. Ann Bot-London 103:533-542

Muller PY, Janovjak H, Miserez AR, Dobbie Z (2002) Processing of gene expression data generated by quantitative real-time RT-PCR. Biotechniques 32:1372-1379

Møller BL (2010) Functional diversifications of cyanogenic glucosides. Curr Opin Plant Biol 13:338-347

Neilson EH, Goodger JQD, Motawia MS, Bjarnholt N, Frisch T, Olsen CE, Møller BL, Woodrow IE (2011) Phenylalanine derived cyanogenic diglucosides from Eucalyptus camphora and their abundances in relation to ontogeny and tissue type. Phytochemistry 72:2325-2334

Neilson EH, Goodger JQD, Woodrow IE, Møller BL (2013) Plant chemical defense: at what cost? Trends Plant Sci $18: 250-258$ 
Neilson EH, Edwards AE, Blomstedt CK, Berger B, Møller BL, Gleadow RM (2015) Utilization of a highthroughput shoot imaging system to examine the dynamic phenotypic responses of a $\mathrm{C} 4$ cereal crop plant to nitrogen and water deficiency over time. J Exp Bot (in press)

Niedźwiedź-Siegień I (1998) Cyanogenic glucosides in Linum usitatissimum. Phytochemistry 49:59-63

Nielsen KA, Olsen CE, Pontoppidan K, Møller BL (2002) Leucine-derived cyano glucosides in barley. Plant Physiol 129:1066-1075

Ohnmeiss TE, Baldwin IT (2000) Optimal defense theory predicts the ontogeny of an induced nicotine defense. Ecology 81:1765-1783

Pellisser V, Maurel N, Machon N (2013) Multi-scale assessment of pollination of Lotus corniculatus (L.) in a periurban fringe. Plant Ecol Divers 6:195-203

Saito S, Motawia MS, Olsen CE, Møller BL, Bak S (2012) Biosynthesis of rhodiocyanosides in Lotus japonicus: Rhodiocyanoside A is synthesized from (Z)-2-methylbutanaloxime via 2-methyl-2-butenenitrile. Phytochemistry $77: 260-267$

Sansenya S, Opassiri R, Kuaprasert B, Chen CJ, Ketudat Cairns JR (2011) The crystal structure of rice (Oryza sativa L.) Os4BGlu12, an oligosaccharide and tuberonic acid glucoside-hydrolyzing $\beta$-glucosidase with significant thioglucohydrolase activity. Arch Biochem Biophys 510:62-72

Sato S, Nakamura Y, Kaneko T (2008) Genome structure of the legume, Lotus japonicus. DNA Res 15:227-239

Selmar D, Lieberei R, Biehl B (1988) Mobilization and utilization of cyanogenic glycosides. Plant Physiol 86:711716

Smith CR, Weisleder D, Miller RW, Palmer IS, Olson OE (1980) Linustatin and neolinustatin: cyanogenic glycosides of linseed meal that protect animals against selenium toxicity. J Org Chem 45:507-510

Sparkes IA, Runions J, Kearns A, Hawes C (2006) Rapid, transient expression of fluorescent proteins in tobacco plants and generation of stably transformed plants. Nat Protoc 1:2019-2025

Stephenson AG (1982) Iridoid glycosides in the nectar of Catalpa speciosa are unpalatable to nectar thieves. J Chem Ecol 8:1025-1034

Straus SY, Irwin RE, Lambrix VM (2004) Optimal defence theory and flower petal colour predict variation in the secondary chemistry of wild radish. J Ecol 92:132-141

Takos A, Lai D, Mikkelsen L, Hachem MA, Shelton D, Motawia MS, Olsen CE, Wang TL, Martin C, Rook F (2010) Genetic screening identifies cyanogenesis-deficient mutants of Lotus japonicus and reveals enzymatic specificty in hydroxynitrile glucoside metabolism. Plant Cell 22:1605-1619 
Takos AM, Knudesen C, Lai D, Kannangara R, Mikkelsen L, Motawia MS, Olsen CE, Sata S, Tabata S, Jørgensen K, Møller BL, Rook F (2011) Genomic clustering of cyanogenic glucoside biosynthetic genes aids their identification in Lotus japonicus and suggests the repeated evolution of this chemical defence pathway. Plant $\mathbf{J}$ 68:273-286

Tamura K, Stecher G, Peterson D, Filipski A, Kumar S (2013) MEGA6: molecular evolutionary genetics analysis version 6.0. Mol Biol Evol 30:2725-2729

Tawaha KA, Hudaib MM (2012) Chemical composition of the essential oil from flowers, flower buds and leaves of Thymus capitatus Hoffmanns. \& Link from Jordan. J Essent Oil Bear Pl 15:988-996

Voinnet O, Rivas, S, Mestre P, Baulcombe D (2003) An enhanced transient expression system in plants based on suppression of gene silencing by the p19 protein of tomato bushy stunt virus. Plant J 23:949-956

Wagner D (2000) Pollen viability reduction as a potential cost of ant association for Acacia constricta (Fabaceae). Am J Bot 87:711-715

Wang Q, Trimbur D, Graham R, Warren RAJ, Withers SG (1995) Identification of the acid/base catalyst in Agrobacterium faecalis $\beta$-glucosidase by kinetic analysis of mutants. Biochemistry-US 34:14554-14562

Webber BL, Woodrow IE (2008) Intra-plant variation in cyanogenesis and the continuum of foliar plant defense traits in the rainforest tree Ryparosa kurrangii (Achariaceae). Tree Physiol 28:977-984

Withers SG, Warren RAJ, Street IP, Rupitz K, Kempton JB, Aebersold R (1990) Unequivocal demonstration of the involvement of a glutamate residue as a nucleophile in the mechanism of a 'retaining' glycosidase. J Am Chem Soc 112:5887-5889

Zagrobelny M, Bak S, Rasmussen AV, Jørgensen B, Naumann CM, Møller BL (2004) Cyanogenic glucosides and plant-insect interactions. Phytochemistry 65:293-306 


\section{FIGURE LEGENDS}

Fig. 1 Cyanogenesis from apical leaves and mature flowers of L. japonicus MG20 and cyd mutant plants, and HNG species detected in flowers. (A) Detection of cyanogenesis by Feigl-Anger paper from, MG20: wild type plants, cyd2-2: loss of function mutant of BGD2 gene, cyd1: loss of function mutant of CYP79D3 gene, and cyd4: loss of function mutant of CYP736A2 gene, (representative of $n=3$ experiments). (B) Extracted ion chromatogram peaks from LC-MS showing HNG species in flowers from plants described in (A) are linamarin (light-blue, $[\mathrm{M}+\mathrm{Na}]^{+}=$ 270 ), rhodiocyanosides D and A (red, $[\mathrm{M}+\mathrm{Na}]^{+}=282$ ) and lotaustralin (dark-blue, $[\mathrm{M}+\mathrm{Na}]^{+}=284$ ). (representative of $n=3$ experiments).

Fig. 2 Tissue specific cyanogenesis from L. japonicus MG20 flowers and HNG content of flower and apical leaf tissues. (A) Cyanogenesis, detected by Feigl-Anger paper, at different flower developmental stages (top to bottom): flower bud, early flower, mature flower, and pod. (B) Cyanogenesis, detected by Feigl-Anger paper, of tissues from mature flowers (top to bottom): sepal, standard, wing, keel and reproductive organs. (representative of $n=3$ experiments for both A and B). (C) The HNG content of L. japonicus MG20 flower and apical leaf tissues determined by LC-MS. Fresh plant material was extracted in $85 \%(\mathrm{v} / \mathrm{v})$ methanol and identity and quantification of HNGs was based on comparison of LC-MS peak areas to known standards and confirmed by MS2 spectral analysis (SE was calculated using 4 biological replicates). RO: reproductive organs.

Fig. 3 Amino acid alignment of BGD3, BGD2 and BGD4. The alignment was made using Molecular Evolutionary Genetics Analysis (MEGA) software version 6 (Tamura et al., 2013). The critical G209/G211 residue for accomodating $\alpha$-HNG substrates by BGD3 and BGD2 respectively is indicated by red box, this residue is V211 in BGD4. The conserved E206 and E420 residues (BGD3 numbering), which have roles as acid/base catalyst and nucleophile respectively, are indicated by red arrows.

Fig. 4 Expression of $B G D$ gene transcripts in L. japonicus MG20 tissues. (A) Relative gene transcript levels in flower internal tissues (keel and reproductive organ) and external tissues (standard and wing). (B) Relative gene transcript levels in apical leaves, $B G D 3$ expression is not detectable. Transcript levels were determined by qPCR of cDNAs reverse transcribed from total RNA samples. Relative transcript abundance was obtained by normalizing the data with the reference gene (RNA pol II), and SE was calculated using 3 biological replicates.

Fig. 5 Transient expression of $B G D$ genes in tobacco plants and activity assays of leaf discs with HNG substrates. (A) Cyanogenesis from leaf discs incubated with $\alpha$-HNG substrates detected by Feigl-Anger paper (representative of $\mathrm{n}=3$ experiments). Substrates are Pru: prunasin, Lot: lotaustralin and Lin: linamarin. (B) Hydrolysis of the $\gamma$-HNG 
substrate rhodiocyanoside A (Rho A) by leaf discs as measured by LC-MS ( $\mathrm{n}=3$ ). The \% peak area remaining after 30 min incubation is graphed.

Fig. 6 Cyanogenesis from flowers and leaves of L. japonicus natural accessions. Detection of cyanogenesis by FeiglAnger paper from plant tissues (left to right) keel, reproductive organs, and apical leaf (representative of $n=5$ experiments).

Fig. 7 Detection of HNGs and HNdGs in L. japonicus MG20 flower nectar and hydrolysis of these compounds in macerated mature flowers. (A) Extracted ion chromatogram peaks from LC-MS of nectar washed from flowers with water are (1) linamarin (light-blue, $[\mathrm{M}+\mathrm{Na}]^{+}=270$ ), (2) rhodiocyanosides $\mathrm{D}$ and $\mathrm{A}$ (red, $[\mathrm{M}+\mathrm{Na}]^{+}=282$ ), (3) diglycosides of the rhodiocyanoside $\mathrm{A} / \mathrm{D}$ aglycones (brown, $[\mathrm{M}+\mathrm{Na}]^{+}=444$ ), (4) lotaustralin (dark-blue, $[\mathrm{M}+\mathrm{Na}]^{+}=$ 284 ) and (5) diglycoside of the lotaustralin aglycone (green, $[\mathrm{M}+\mathrm{Na}]^{+}=446$ ). Water used to wash nectar from flowers contains no HNGs or HNdGs. Nectar mixed with flax seeds contains an additional peak (6) neolinustatin (light-green, $[\mathrm{M}+\mathrm{Na}]^{+}=446$ ). When analysed alone, neolinustatin (6) in the flax seeds extracts has an identical retention time as in the mixture of the nectar sample with flax seeds extract. (representative chromatograms of $n=3$ nectar washes). (B) Hydrolysis of HNGs and HNdGs in L. japonicus MG20 flowers determined by LC-MS. Flowers $(\mathrm{n}=5)$ were macerated in $20 \mathrm{mM}$ MES pH 6.5 and incubated at $30^{\circ} \mathrm{C}$. The HNG and $\mathrm{HNdG}$ content was compared by LC-MS at $\mathrm{t}=0$ and $\mathrm{t}=240 \mathrm{~min}$ and the \% peak area of each species remaining determined. Rho.HNdG: diglycosides of the rhodiocyanoside A/D aglycones, Lot HNdG: diglycoside of the lotaustralin aglycone. 
Fig. 1
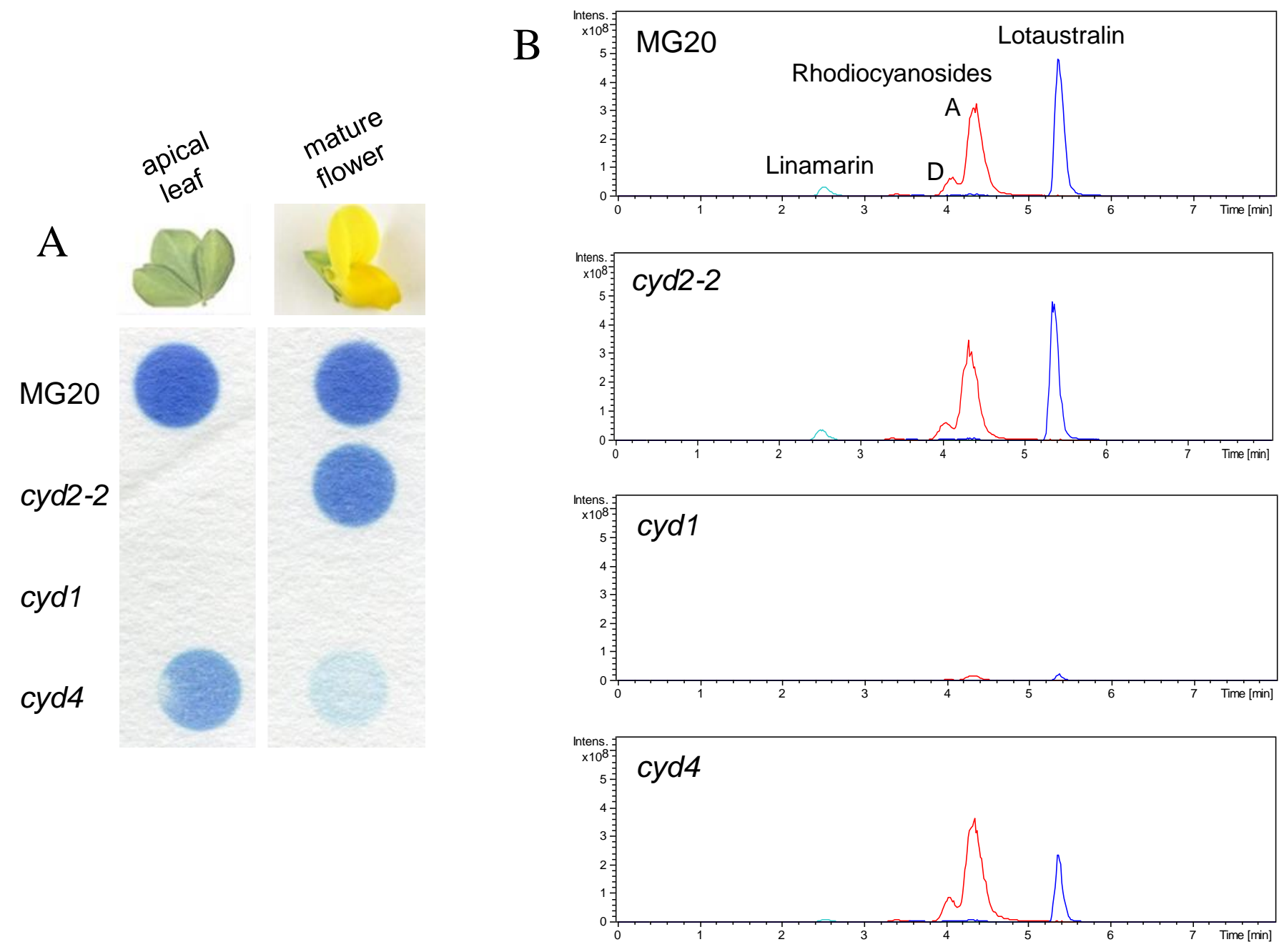
Fig. 2
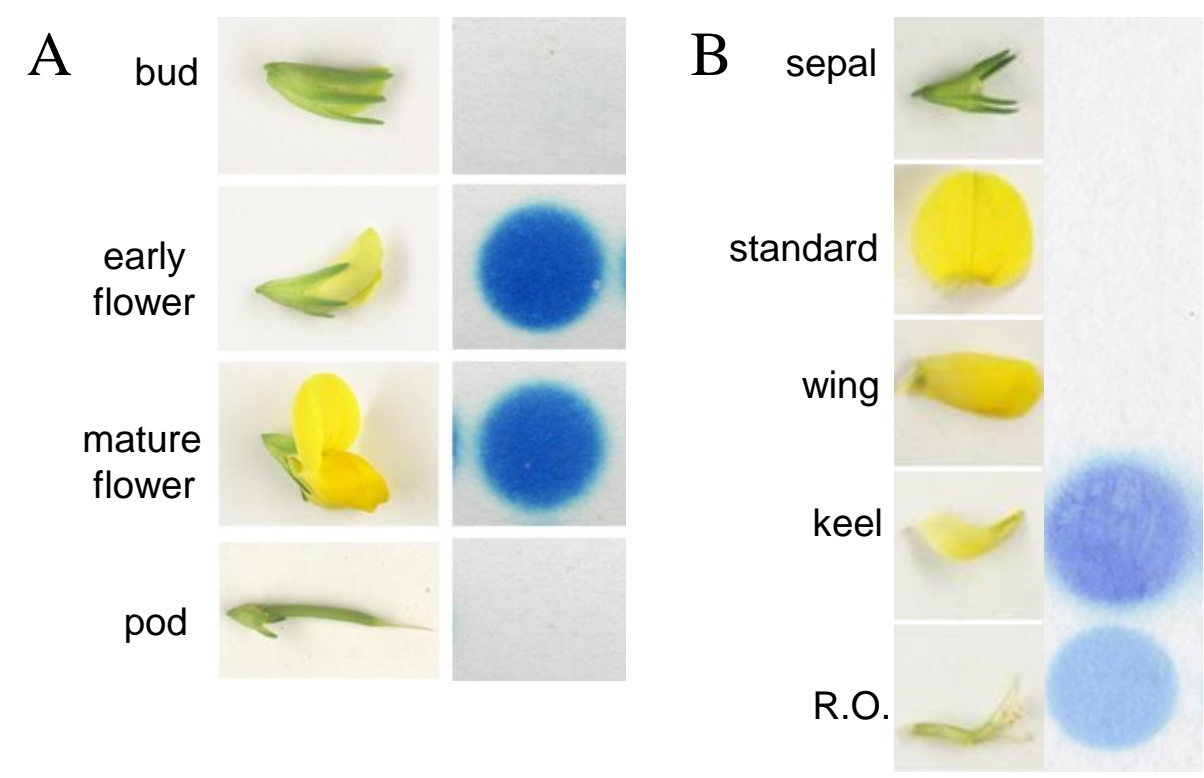

C

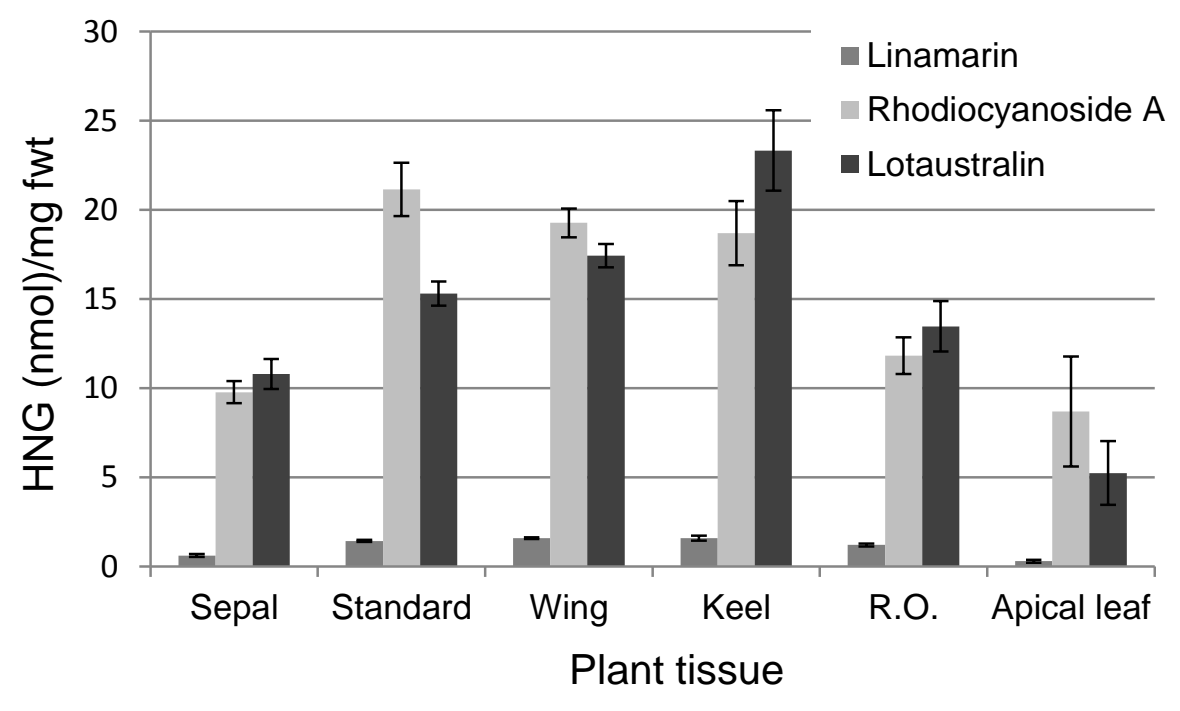


Figure 3

Click here to download Colour figure: Figure 3.pptx

Fig. 3

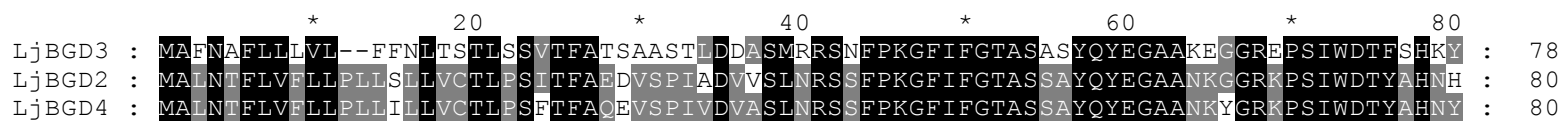

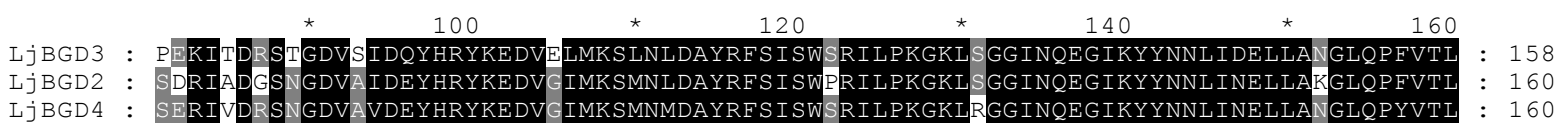

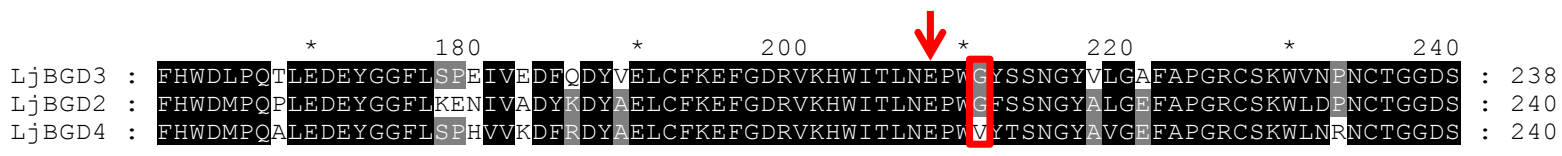

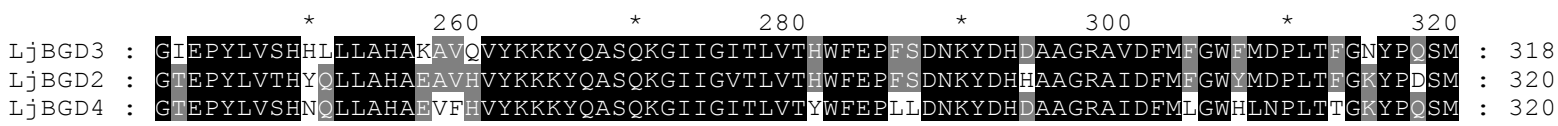

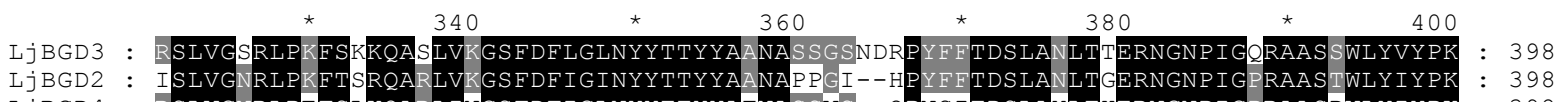

$\begin{array}{ll}\text { LjBGD } 4: \text { RSLVGNRLPESLKQARLINGSFDFIGLNYYTTYYATNASSVI--QPNS ITDSLAYLTHERNGNPIGPRAASDWLYIYPK } & : 398\end{array}$

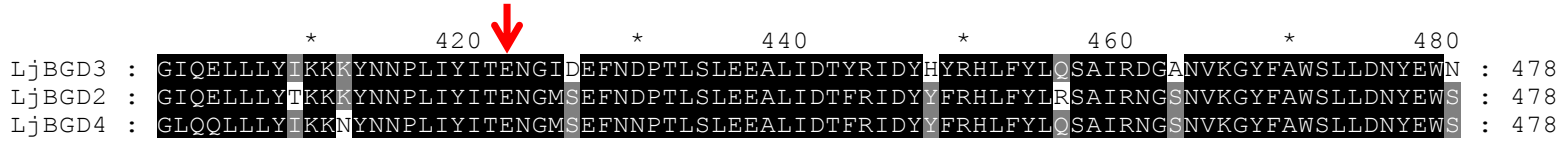

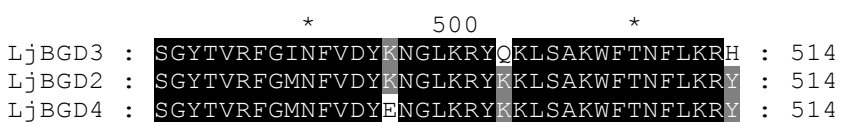


Click here to download Screen/black and white figure: Figure 4.tif

Fig. 4

A

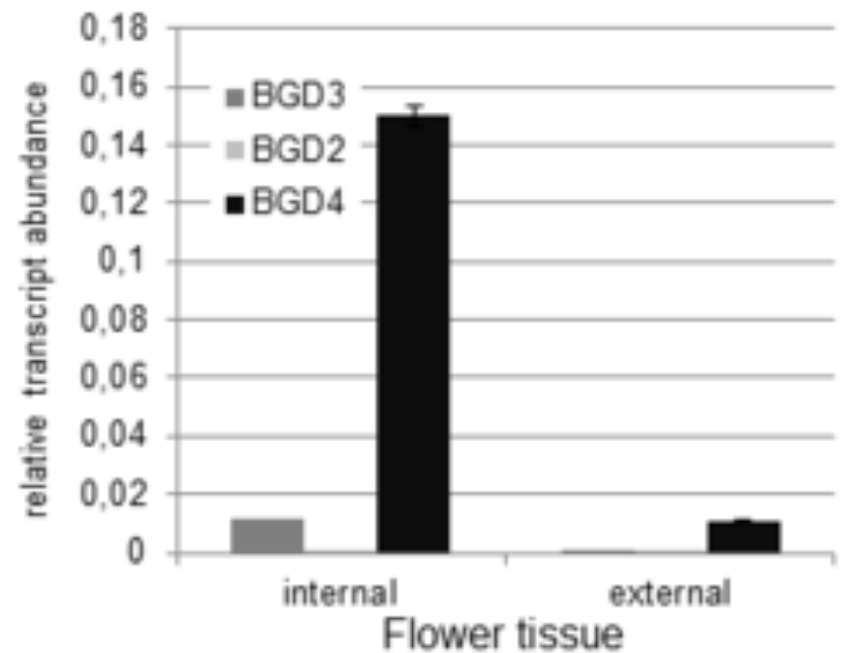

B

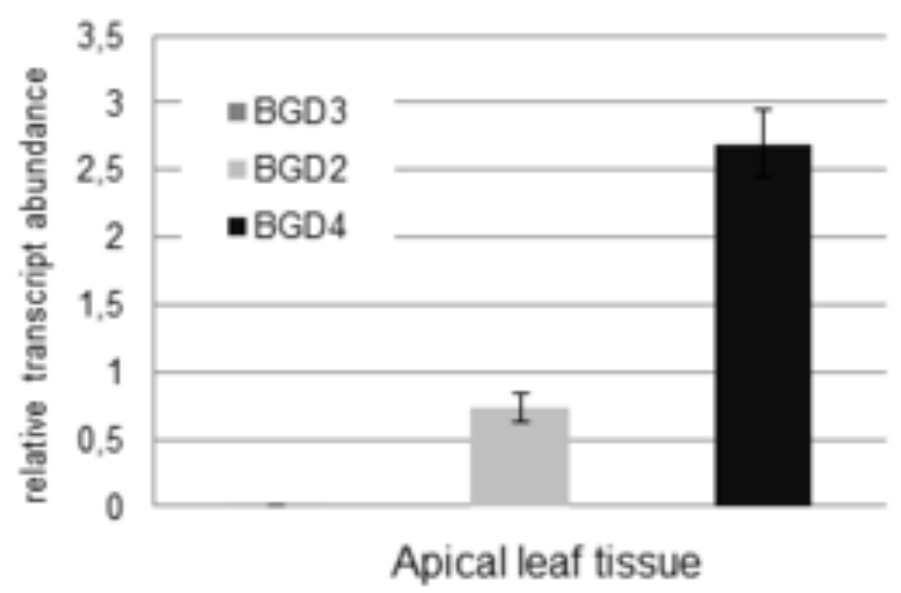

Flower tissue

Apical leaf tissue 
Click here to download Colour figure: Figure 5.tif

Fig. 5
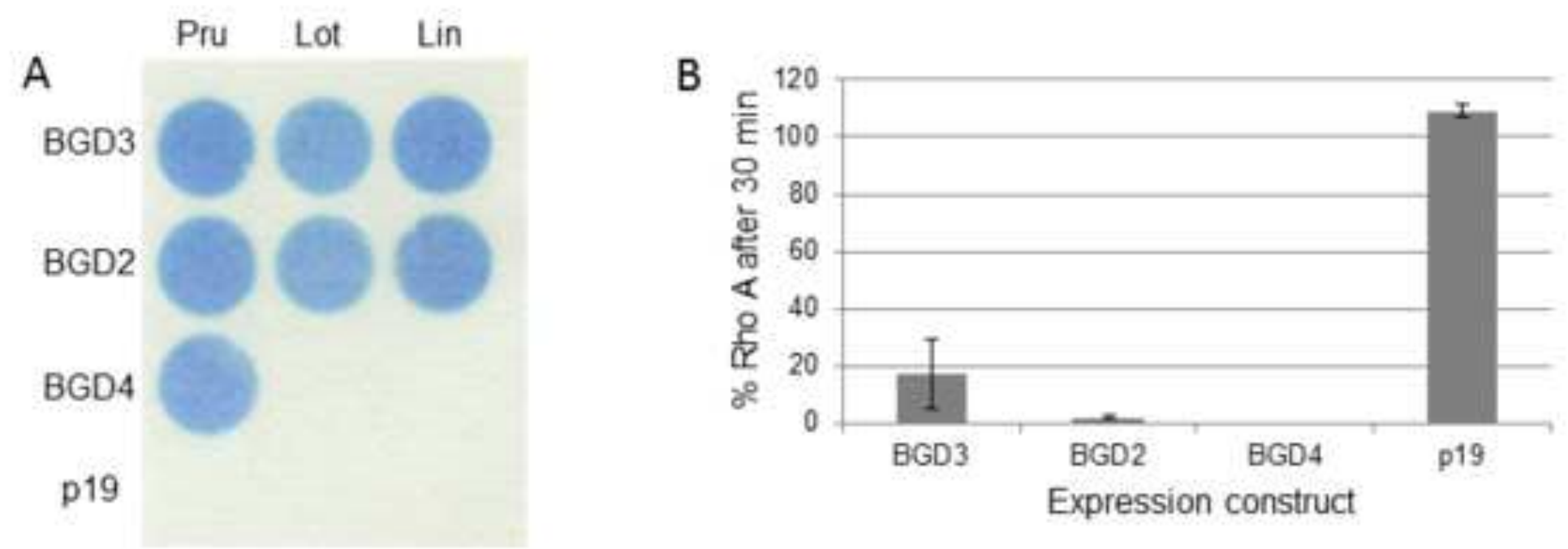
Fig. 6

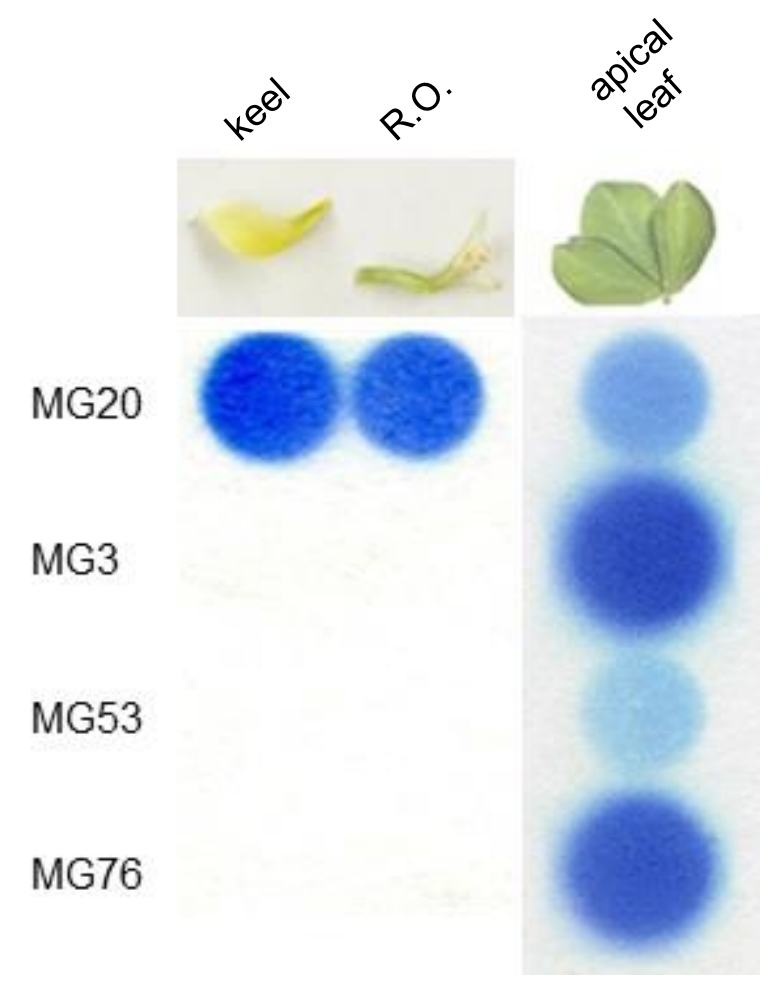


Fig. 7
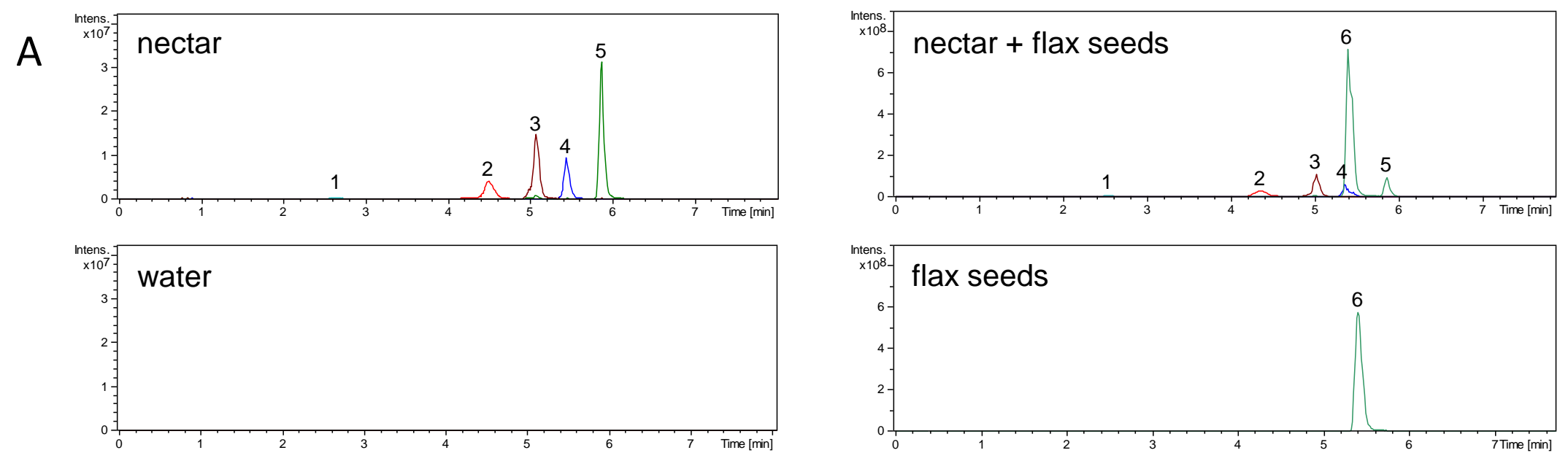

B

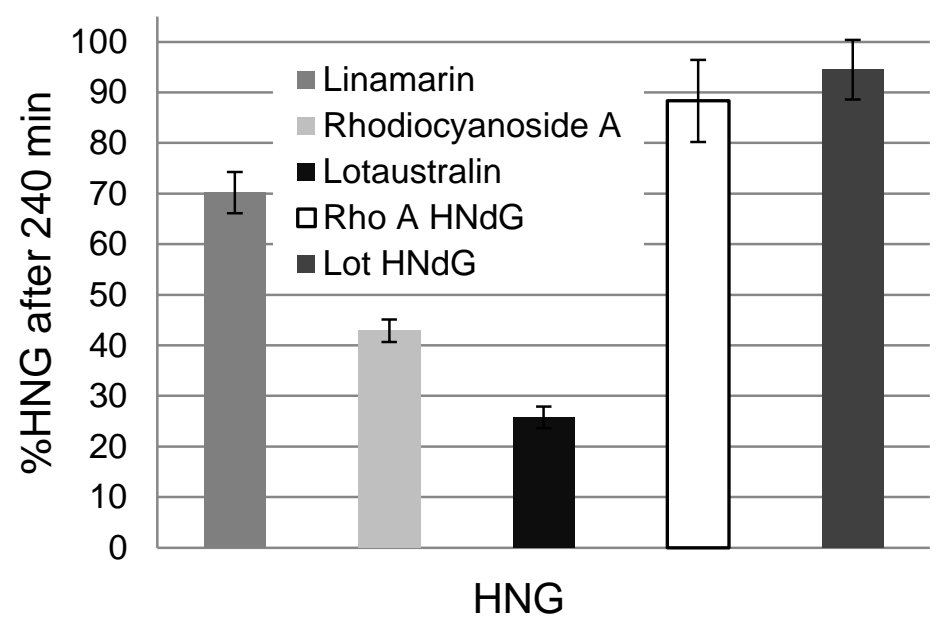


Supplemental Tables
Click here to download Supplementary material: Supplementary Tables Lai et al 2015.pdf 


\title{
Supplementary Figures
}

Click here to download Supplementary material: Supplementary Figures Lai et al 2015.pdf

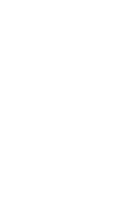

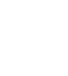

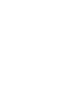

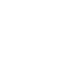
(1) - n (1) 列

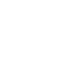
(1) (1)

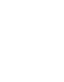

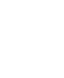

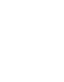

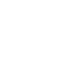

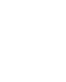

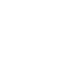

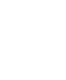

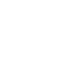

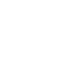

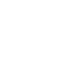
.

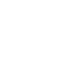

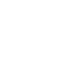

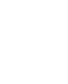

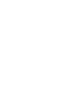

